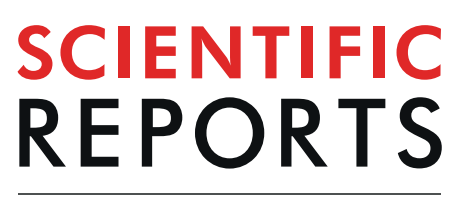

\title{
Assessment of the optimal cutoff value of fasting plasma glucose to establish diagnosis of gestational diabetes mellitus in Chinese women
}

\begin{abstract}
Bing Yan ${ }^{1,6}$, Ya-xin Yu ${ }^{4,6}$, Yin-ling Chen ${ }^{3}$, Wei-juan Su ${ }^{2}$, Yin-xiang Huang ${ }^{1}$, Mu-lin Zhang ${ }^{2}$, Bing-kun Huang ${ }^{2}$, Li-li Han ${ }^{5}$, Hai-qu Song ${ }^{2 *}$ \& Xue-jun $\mathrm{Li}^{1,2 *}$

Our aim is to assess the optimal cutoff value of fasting plasma glucose (FPG) in Chinese women at 24-28 weeks' gestation by performing oral glucose tolerance test (OGTT) to improve diagnostic rate of gestational diabetes mellitus (GDM). Data were derived from the Medical Birth Registry of Xiamen. A FPG cutoff value of $5.1 \mathrm{mmol} / \mathrm{L}$ confirmed the diagnosis of GDM in 4,794 (6.10\%) pregnant women. However, a FPG cutoff value of $4.5 \mathrm{mmol} / \mathrm{L}$ should rule out the diagnosis of GDM in 35,932 (45.73\%) pregnant women. If we use this cutoff value, the diagnosis of GDM to about $27.3 \%$ of pregnant women will be missed. Additionally, a 75-g OGTT was performed in pregnant women with FPG values between 4.5 and $5.1 \mathrm{mmol} / \mathrm{L}$, avoiding the performance of formal $75-\mathrm{g}$ OGTT in about $50.37 \%$ pregnant women. Meanwhile, according to maternal age and pre-pregnancy BMI categories, with FPG values between $4.5 \mathrm{mmol} / \mathrm{L}$ and $5.1 \mathrm{mmol} / \mathrm{L}$, which had high sensitivity, to improve the diagnostic rate of GDM in all groups. Further researches are needed to present stronger evidences for the screening value of FPG in establishing the diagnosis of GDM in pregnant women.
\end{abstract}

Gestational diabetes mellitus (GDM) is defined as any degree of glucose intolerance with first recognition or onset during pregnancy ${ }^{1}$, which is an increasing public health problem. Worldwide, a total of 21.3 million women experienced hyperglycemia during pregnancy and nearly $86.4 \%$ of pregnant women were diagnosed to have GDM in $2017^{2}$. Furthermore, studies indicate that compared with European women, Asian women have a higher incidence of $\mathrm{GDM}^{3,4}$. Chinese pregnant women experience an elevated incidence of GDM due to China's rapid economic and social development, which led to the change of lifestyle in the past several decades ${ }^{5}$. In 2015 , a total of 2.90 million pregnant women suffered from GDM in China ${ }^{6}$, resulting in the implementation of one-child policy by the Chinese government.

Consequently, GDM has become a major public health problem because of China's limited social and medical resources. Hence, in China, the health burden of GDM is significant. One study reported that the cost of pregnant women with GDM was $¥ 6,677.37$ more than that of pregnant women without GDM. As a result, in 2015, the total burden cost of GDM was calculated to be $¥ 19.36$ billion $^{6}$, which is equal to $0.5 \%$ of the total public expenditure for healthcare and medical and family planning in $\mathrm{China}^{7}$. Due to the silent nature of GDM, an oral glucose tolerance test (OGTT)was performed to establish the diagnosis of GDM in pregnant women at 24-28 weeks' gestation ${ }^{8}$.

Considering that the huge economic cost and social resource consumption for the diagnosis of GDM by implementing OGTT, not all pregnant women can perform a 75-g OGTT in some remote rural areas because of China's limited medical and social resources ${ }^{9,10}$. Therefore, we can choose to establish a relatively reliable FPG threshold in OGTT as the reference value, so as to judge whether to continue to carry out the remaining experiments in OGTT, and ultimately achieve resource saving and improve diagnostic rate. One study reported that when the risk of GDM was between $1.0 \%$ and $4.2 \%$, performing fasting plasma glucose (FPG) test followed by OGTT was the cost-effective method ${ }^{11}$. Moreover, another research compared the costs of the following

${ }^{1}$ Xiamen Diabetes Institute, Xiamen, China. ${ }^{2}$ Department of Endocrinology and Diabetes, The First Affiliated Hospital of Xiamen University, Xiamen, China. ${ }^{3}$ Medical College of Xiamen University, Xiamen, China. ${ }^{4}$ Xinglin Branch, The First Affiliated Hospital of Xiamen University, Xiamen, China. ${ }^{5}$ Fujian Medical University, Fuzhou, China. ${ }^{6}$ These authors contributed equally: Bing Yan and Ya-xin Yu. *email: haiqs@163.com; xmlixuejun@163.com 
three strategies in establishing the diagnosis of GDM: 100-g OGTT, 75-g OGTT, and FPG test of the OGTT. Consequently, the research revealed that performing FPG test was the ideal method ${ }^{12}$. Therefore, performing FPG test is recommended to establish the diagnosis of GDM at 24-28 weeks' gestation. Additionally, initially performing an FPG test prevents the need of performing many subsequent OGTTs, hence reducing the health burden of the Chinese societies and families.

The advantages of performing FPG test to establish the diagnosis of GDM include the following: the test is cheap, reproducible, and reliable and has no vomiting response, response that is usually evident when performing OGTT or the glucose challenge test. FPG test can be performed in pregnant women who were unable to tolerate glucose-containing drinks. FPG test was performed to establish the diagnosis of GDM ${ }^{13}$. Zhu et al. reported that during the first prenatal visit, increased FPG level was strongly associated with GDM at 24-28 weeks' gestation in China $^{14}$. However, there were only two similar studies that assessed the sensitivity and specificity of FPG value in establishing the diagnosis of GDM at 24-28 weeks' gestation in China, stressing that if the FPG cutoff value was between $4.4 \mathrm{mmol} / \mathrm{L}$ and $5.1 \mathrm{mmol} / \mathrm{L}$, the pregnant women should undergo OGTT ${ }^{14,15}$. Whereas, one of the disadvantages in the above studies was that the data from the above study were derived from a hospital that consisted of a small sample size due to the following reason: rural residents rarely visited to the general hospital.

Chinese women tend to get pregnant at young ages ${ }^{16}$ is different from the other countries or healthcare systems, especially in developed countries, where women get pregnancy at older ages ${ }^{17}$. As well, pre-pregnancy body mass index (BMI) is a known risk factor for $\mathrm{GDM}^{18,19}$. In addition, studies revealed pre-pregnancy BMI might be as a predictor for GDM. Whereas, compared to population in other races, the BMI levels of Asians might be generally lower, which was contributed to ethnic differences ${ }^{20,21}$.

Therefore, this study aimed to assess the sensitivity and specificity of FPG value to establish the diagnosis of GDM based on maternal age and pre-pregnancy BMI categories in China with a registered data and to improve the diagnostic rate of GDM, hence avoiding the performance of a number of OGTTs and consequently reducing the health burden of the Chinese societies and families.

\section{Materials and Methods}

Study design. The Medical Birth Registry of Xiamen (MBRX) recorded the results of a 75-g OGTT for pregnant women and implemented the International Association of Diabetes and Pregnancy Study Group (IADPSG) criteria (one-step approach). Over 7 years, from March 1, 2011, to March30, 2018, pregnant women at 24-28 weeks' gestation who were registered at the MBRX underwent the 75-g OGTT in Xiamen. According to the GDM diagnostic criteria, the venous plasma glucose values were recorded and analyzed. We created the receiver operating characteristic (ROC) curves to detect the FPG value and subsequently to establish the diagnosis of GDM based on the result of the 75-g OGTT, which is the standard method, and each point as a screening node was analyzed.

Definition. The diagnosis of GDM could be established by the Ministry of Health in China according to IADPSG $^{22}$ when any of the following FPG values were met or exceeded: $0 \mathrm{~h}$, greater than or equal to5.1 mmol/L; $1 \mathrm{~h}$, greater than or equal to $10.0 \mathrm{mmol} / \mathrm{L}$; and $2 \mathrm{~h}$, greater than or equal to $8.5 \mathrm{mmol} / \mathrm{L}$. BMI was calculated on account of self-reported weight and measured height. According to World Health Organization recommendations for Asian population ${ }^{23}$, the pregnant women were classified into four groups: underweight, BMI $<18.5 \mathrm{~kg} /$ $\mathrm{m}^{2}$; normal weight, $18.5-23.9 \mathrm{~kg} / \mathrm{m}^{2}$; overweight, $24.0-27.9 \mathrm{~kg} / \mathrm{m}^{2}$; and obesity, $\geq 28 \mathrm{~kg} / \mathrm{m}^{2}$. Maternal age was classified into four groups: $\leq 25$ years; $26-30$ years; $31-35$ years; and $>35$ years.

Informed consent and ethics statements. The ethics committee of the First Affiliated Hospital of Xiamen University approved our study waived the need for informed consent, which composed and worked in accordance with the Chinese GCP and relevant regulations. The application number was KYH2018-007. In addition, this study was carried out in accordance with the rules of the Declaration of Helsinki of 1975, revised in 2013.

Statistical analysis. The characteristics of study population were analyzed by SPSS version 17.0 statistical software (SPSS Inc., IL, USA). Continuous variables were showed as Median (min-mix). Discontinuous variables were expressed as $n(\%)$, which were analyzed by Chi-square $\left(\chi^{2}\right)$ test. This study compared FPG cutoff values across pre-pregnancy BMI and maternal age categories. Receiver operating characteristic (ROC) curve analysis was conducted to identify the diagnostic power of FPG value of OGTT at pre-pregnancy in predicting development of GDM. The level of statistical significance is set at 0.05 .

\section{Results}

Characteristics of study population. A total of 78,572 pregnant women (age range, 18-53 years old) registered at the MBRX underwent a 75-g OGTT. Most of the pregnant women $(51,600)$ had education levels higher than 9 years. Additionally, the parity of the 36,869 (53.00\%) pregnant women was more than two times (Table 1). A total of 13,658 pregnant women were diagnosed to have GDM on account of maternal age and pre-pregnancy BMI categories based on the IADPSG criteria. The results of performing a 75-g OGTT in order to establish the diagnosis of GDM revealed that the following pregnant women have met or exceeded the FPG values: $0 \mathrm{~h}$ ( $\geq 5.1 \mathrm{mmol} / \mathrm{L}), 2,753$ pregnant women; $1 \mathrm{~h}(\geq 10.0 \mathrm{mmol} / \mathrm{L}), 3,088$ pregnant women; and $2 \mathrm{~h}(\geq 8.5 \mathrm{mmol} / \mathrm{L})$, 3,257 pregnant women. The diagnostic rates of GDM were $18.8 \%, 21.07 \%$, and $22.2 \%$, respectively. Furthermore, the diagnostic rate of GDM was $35.7 \%$ following the FPG criteria in the OGTT. To assess the FPG value of OGTT to establish the diagnosis of GDM at 24-28 weeks' gestation, the ROC curves are shown in Figure 1 . The area under the ROC curve was 0.752 (95\% CI, 0.747-0.757; SE, 0.003; $P<0.001)$. 


\begin{tabular}{|c|c|c|}
\hline & $\mathbf{N}$ & $\begin{array}{l}\text { Median (min- } \\
\max ) \text { or } n(\%)\end{array}$ \\
\hline Age, years & 77,859 & $28(18-53)$ \\
\hline BMI, kg/m $\mathrm{m}^{2}$ & 77,859 & $20.6(13.3-44.4)$ \\
\hline Systolic blood pressure, $\mathrm{mmHg}$ & 51,788 & $107(70-160)$ \\
\hline Diastolic blood pressure, $\mathrm{mmHg}$ & 51,794 & $65(40-105)$ \\
\hline Education, No. & 68,066 & $100 \%$ \\
\hline$\leq 9$ years & 16,900 & $24.83 \%$ \\
\hline$>9$ years & 511,600 & $75.17 \%$ \\
\hline Family history of diabetes, No. & 73,670 & $100 \%$ \\
\hline Yes & 1,825 & $2.48 \%$ \\
\hline No & 71,845 & $97.52 \%$ \\
\hline Family history of hypertension, No & 73,670 & $100 \%$ \\
\hline Yes & 3,849 & $5.22 \%$ \\
\hline No & 69,821 & $94.78 \%$ \\
\hline Fasting glucose in first trimester, mmol/L & 46,183 & $4.7(2.9-8.7)$ \\
\hline \multicolumn{3}{|l|}{ OGTT at week $24-28, \mathrm{mmol} / \mathrm{L}$} \\
\hline Fasting glucose & 78,572 & $4.5(3.0-14.3)$ \\
\hline 1-h glucose & 78,572 & $7.8(20-23.2)$ \\
\hline 2-h glucose & 78,572 & $6.6(2.5-23.9)$ \\
\hline Parity, No. & 69,559 & $100 \%$ \\
\hline 1 & 32,690 & $47.00 \%$ \\
\hline$\geq 2$ & 36,869 & $53.00 \%$ \\
\hline
\end{tabular}

Table 1. Characteristics of study population. BMI, body mass index; OGTT, oral glucose tolerance test.

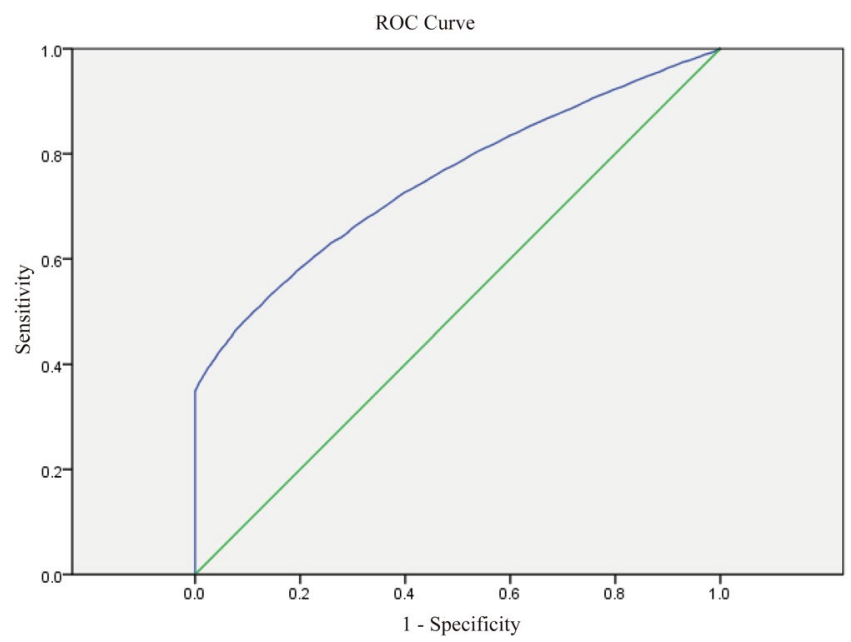

Figure 1. The receiver operating characteristic (ROC) curve of the participants in this study (the area under the ROC curve was $0.752 ; 95 \% \mathrm{CI}, 0.747-0.757$; SE, $0.003 ; P<0.001$ ).

The overall association between FPG cutoff value and GDM diagnosis. FPG value was more than $5.1 \mathrm{mmol} / \mathrm{L}$, the diagnosis of GDM (6.10\%) in pregnant women was confirmed. As shown in Table 2, with the cutoff FPG value of $4.5 \mathrm{mmol} / \mathrm{L}, 72.7 \%$ of pregnant women were diagnosed to have GDM with specificity of 0.600 . If the FPG value of $4.5 \mathrm{mmol} / \mathrm{L}$ was the cutoff value to identify who should undergo the 75 -g OGTT, then $50.37 \%$ ( $44.27 \%$ with values were less than $4.5 \mathrm{mmol} / \mathrm{L}$ plus $6.10 \%$ with values were greater than $5.1 \mathrm{mmol} / \mathrm{L}$ ) of pregnant women could avoid the performance of a 75-g OGTT with the probability that $27.3 \%$ of pregnant women with GDM may miss to undergo a 75-g OGTT. If the FPG value of $4.4 \mathrm{mmol} / \mathrm{L}$ or $4.3 \mathrm{mmol} / \mathrm{L}$ serves as the cutoff value, the missed percentage of pregnant women who should undergo a 75 -g OGTT would be $20.2 \%$ or $14.2 \%$ with the specificity was 0.474 and 0.350 respectively.

The association between FPG cutoff value and GDM diagnosis according to maternal age categories. $1,837(9.6 \%)$ women were diagnosed as GDM for maternal age $\leq 25$ years, 6,085 (15.9\%) women for maternal age among 26 to 30 years, 3,880 (24.8\%) women for maternal age among 31 to 35 years, and 1,766 (36.0\%) women for maternal age $>35$ years, $P<0.001$. To evaluate the FPG value of OGTT to establish the diagnosis of GDM 


\begin{tabular}{|l|l|l|l|l|l|l|l|l|l|l|}
\hline $\begin{array}{l}\text { Cut point } \\
(\mathbf{m m o l} / \mathbf{L})\end{array}$ & $\begin{array}{l}\text { At or above the } \\
\text { value, } \mathbf{n}(\%)\end{array}$ & Sensitivity & Specificity & FPR & FNR & $\begin{array}{l}\text { Youden } \\
\text { index }\end{array}$ & PLR & NLR & PPV & NPV \\
\hline 4.0 & $72457(92.22)$ & 0.968 & 0.088 & 0.032 & 0.912 & 0.056 & 1.061 & 0.364 & 0.926 & 0.189 \\
\hline 4.1 & $67954(86.49)$ & 0.943 & 0.152 & 0.057 & 0.848 & 0.095 & 1.112 & 0.375 & 0.877 & 0.294 \\
\hline 4.2 & $61580(78.37)$ & 0.906 & 0.242 & 0.094 & 0.758 & 0.148 & 1.195 & 0.388 & 0.813 & 0.415 \\
\hline 4.3 & $53896(68.59)$ & 0.858 & 0.350 & 0.142 & 0.650 & 0.208 & 1.320 & 0.406 & 0.743 & 0.530 \\
\hline 4.4 & $45030(57.31)$ & 0.798 & 0.474 & 0.202 & 0.526 & 0.272 & 1.517 & 0.426 & 0.671 & 0.636 \\
\hline 4.5 & $35932(45.73)$ & 0.727 & 0.600 & 0.273 & 0.400 & 0.327 & 1.818 & 0.455 & 0.605 & 0.723 \\
\hline 4.6 & $27585(35.11)$ & 0.648 & 0.712 & 0.352 & 0.288 & 0.360 & 2.250 & 0.494 & 0.549 & 0.789 \\
\hline 4.7 & $20454(26.03)$ & 0.577 & 0.807 & 0.423 & 0.193 & 0.384 & 2.990 & 0.524 & 0.512 & 0.844 \\
\hline 4.8 & $14554(18.52)$ & 0.505 & 0.882 & 0.495 & 0.118 & 0.387 & 4.280 & 0.561 & 0.493 & 0.887 \\
\hline 4.9 & $10122(12.88)$ & 0.444 & 0.938 & 0.556 & 0.062 & 0.382 & 7.161 & 0.593 & 0.515 & 0.919 \\
\hline 5.0 & $7056(8.98)$ & 0.394 & 0.975 & 0.606 & 0.025 & 0.369 & 15.760 & 0.622 & 0.609 & 0.942 \\
\hline 5.1 & $4794(6.10)$ & 0.349 & 1 & 0.651 & 0 & 0.349 & - & 0.651 & 1.000 & 0.959 \\
\hline
\end{tabular}

Table 2. Fasting glucose plasma cutoff values of gestational diabetes mellitus diagnosis. FPR, false positive ratio; FNR, false negative ratio; PLR, positive likelihood ratio; NLR, negative likelihood ratio; PPV, positive predictive value; NPV, negative predictive value.

\begin{tabular}{|l|l|l|l|l|l|l|l|}
\hline Age (years) & GDM (n/\%) & $\begin{array}{l}\text { No-GDM } \\
(\mathbf{n})\end{array}$ & $\boldsymbol{P}$ value & $\begin{array}{l}\text { Area Under } \\
\text { ROC curve }\end{array}$ & 95CI & SE & P value \\
\hline$\leq 25$ & $1837(9.6)$ & 17272 & & 0.76 & $0.748-0.775$ & 0.007 & $<0.001$ \\
\hline $26-30$ & $6085(15.9)$ & 32140 & $<0.001$ & 0.74 & $0.730-0.746$ & 0.004 & $<0.001$ \\
\hline $31-35$ & $3880(24.8)$ & 11744 & & 0.74 & $0.730-0.750$ & 0.005 & $<0.001$ \\
\hline$>35$ & $1766(36.0)$ & 3135 & & 0.75 & $0.735-0.765$ & 0.008 & $<0.001$ \\
\hline
\end{tabular}

Table 3. The receiver operation characteristic curve of the participants among different maternal age. GDM, gestational diabetes mellitus; ROC, receiver operation characteristic; CI, confidence intervals; SE, standard error.

at 24-28 weeks' gestation based on different maternal age, the ROC curves are shown in Table 3 . The area under the ROC curve of different maternal age was $0.76,0.74,0.74$, and 0.75 , respectively for maternal age $\leq 25,26-30$, $31-35$, and $>35$ years groups.

As presented in Table 4, with the cutoff FPG value of $4.5 \mathrm{mmol} / \mathrm{L}, 70.4 \%$ of pregnant women aged less than 25 years were diagnosed to have GDM with specificity of 0.658 . As well, with the FPG cutoff value of $4.5 \mathrm{mmol} / \mathrm{L}$, $70.6 \%$ of pregnant women aged among 26 to 30 years were diagnosed as GDM with specificity of 0.601 , and $74.9 \%$ of pregnant women aged among 31-35 years were diagnosed as GDM with specificity of 0.542 . Besides, $77.6 \%$ of pregnant women aged more than 35 years were diagnosed as GDM with the specificity of 0.497 .

The association between FPG cutoff value and GDM diagnosis according to pre-pregnancy BMI categories. $\quad 1,511(10.5 \%)$ women were diagnosed as GDM for pre-pregnancy BMI $<18.5 \mathrm{~kg} / \mathrm{m}^{2}, 8,657$ (16.6\%) women for pre-pregnancy BMI among 18.5 to $23.9 \mathrm{~kg} / \mathrm{m}^{2}, 2,743(29.1 \%)$ women for pre-pregnancy BMI among 24.0 to $27.9 \mathrm{~kg} / \mathrm{m}^{2}$, and $657(35.7 \%)$ women for pre-pregnancy BMI $\geq 28 \mathrm{~kg} / \mathrm{m}^{2}$. According to pre-pregnancy BMI categories, the ROC curves are presented in Table 5. The area under the ROC curve of pre-pregnancy BMI categories was $0.66,0.74,0.81$, and 0.83 , respectively for pre-pregnancy BMI $<18.5$ (underweight), $18.5-23.9$ (normal), $24.0-27.9$ (overweight), and $\geq 28 \mathrm{~kg} / \mathrm{m}^{2}$ (obesity) groups.

As presented in Table 6, with the FPG cutoff value of $4.5 \mathrm{mmom} / \mathrm{L}, 54.9 \%$ of pregnant women with pre-pregnancy BMI less than $18.5 \mathrm{~kg} / \mathrm{m}^{2}$ (underweight) were diagnosed as GDM with the specificity of 0.692 . Meanwhile, with the cutoff FPG value of $4.5 \mathrm{mmol} / \mathrm{L}, 70.8 \%$ of pregnant women with pre-pregnancy BMI among 18.5 to $23.9 \mathrm{~kg} / \mathrm{m}^{2}$ (normal) were diagnosed to have GDM with specificity of 0.597 . In addition, with the cutoff FPG value of $4.5 \mathrm{mmol} / \mathrm{L}, 84.7 \%$ or $89.3 \%$ pregnant women with pre-pregnancy BMI among $24-27.9 \mathrm{~kg} / \mathrm{m}^{2}$ (overweight) or $\geq 28.0 \mathrm{~kg} / \mathrm{m}^{2}$ (obesity) were diagnosed as GDM with specificity of 0.485 and 0.391 respectively.

\section{Discussion}

Although it had been reported that FPG was a poor predictor for GDM later in pregnancy based on the FPG level decreases at the end of the first trimester and with a low sensitivity or poor specificity ${ }^{24,25}$, in this study, ROC curve analysis presented that FPG $\geq 4.5 \mathrm{mmol} / \mathrm{L}$ was the optimal threshold for predicting GDM, with a sensitivity of $72.7 \%$ and a specificity of $60.0 \%$.

Our study showed that the diagnostic rate of GDM using $5.1 \mathrm{mmol} / \mathrm{L}$ as the cutoff FPG value based on the IADPSG criteria was only $35.7 \%$. However, another study indicated that the IADPSG criteria diagnosed GDM using the FPG value (55\%) alone for the complete Hyperglycemia and Adverse Pregnancy Outcome (HAPO) cohort study. Interestingly, the diagnostic rate of GDM using the FPG value (5.1 mmol/L) was $47 \%$ in Singapore ${ }^{26}$. Compared with these results, the diagnostic rate is lower in this study. It is clear that the FPG cutoff value of 


\begin{tabular}{|c|c|c|c|c|c|c|c|c|c|c|c|c|}
\hline \multirow[b]{2}{*}{$\begin{array}{l}\text { Cutoff point } \\
(\mathrm{mmol} / \mathrm{L})\end{array}$} & \multicolumn{3}{|l|}{$\leq 25$ years } & \multicolumn{3}{|l|}{$26-30$ years } & \multicolumn{3}{|l|}{$31-35$ years } & \multicolumn{3}{|l|}{$>35$ years } \\
\hline & $\begin{array}{l}\text { At or above } \\
\text { the value, } \\
\text { n (\%) }\end{array}$ & Sensitivity & 1-Specificity & $\begin{array}{l}\text { At or above } \\
\text { the value, } \\
\text { n (\%) }\end{array}$ & Sensitivity & 1-Specificity & $\begin{array}{l}\text { At or above } \\
\text { the value, } \\
\mathrm{n}(\%)\end{array}$ & Sensitivity & 1-Specificity & $\begin{array}{l}\text { At or above } \\
\text { the value, } \\
\text { n (\%) }\end{array}$ & Sensitivity & 1-Specificity \\
\hline 4.0 & $17077(89.37)$ & 0.958 & 0.887 & $35198(92.08)$ & 0.966 & 0.912 & $14838(94.97)$ & 0.974 & 0.942 & $4719(96.29)$ & 0.989 & 0.948 \\
\hline 4.1 & $15714(82.23)$ & 0.931 & 0.811 & $32978(86.27)$ & 0.938 & 0.849 & $14136(90.48)$ & 0.952 & 0.889 & 4567 (93.19) & 0.971 & 0.910 \\
\hline 4.2 & $13850(72.48)$ & 0.885 & 0.708 & $29828(78.03)$ & 0.897 & 0.758 & $13105(83.88)$ & 0.922 & 0.811 & $4287(87.47)$ & 0.948 & 0.833 \\
\hline 4.3 & $11712(61.29)$ & 0.827 & 0.590 & $25993(68.00)$ & 0.841 & 0.649 & $11750(75.20)$ & 0.880 & 0.710 & $3943(80.45)$ & 0.908 & 0.746 \\
\hline 4.4 & $9423(49.31)$ & 0.772 & 0.463 & 21575 (56.44) & 0.779 & 0.524 & $10082(64.53)$ & 0.818 & 0.588 & $3475(70.90)$ & 0.851 & 0.629 \\
\hline 4.5 & $7194(37.65)$ & 0.704 & 0.342 & $17123(44.80)$ & 0.706 & 0.399 & $8284(53.02)$ & 0.749 & 0.458 & $2948(60.15)$ & 0.776 & 0.503 \\
\hline 4.6 & $5224(27.34)$ & 0.624 & 0.236 & $13037(34.11)$ & 0.626 & 0.287 & $6570(42.05)$ & 0.673 & 0.337 & $2434(49.66)$ & 0.704 & 0.380 \\
\hline 4.7 & $3641(19.05)$ & 0.565 & 0.151 & $9515(24.89)$ & 0.554 & 0.191 & $5046(32.30)$ & 0.594 & 0.233 & $1938(38.54)$ & 0.623 & 0.267 \\
\hline 4.8 & $2397(12.54)$ & 0.499 & 0.086 & 6725 (17.59) & 0.488 & 0.117 & $3667(23.47)$ & 0.507 & 0.145 & $1475(30.10)$ & 0.541 & 0.166 \\
\hline 4.9 & $1579(8.26)$ & 0.459 & 0.043 & $4592(12.01)$ & 0.428 & 0.062 & $2600(16.64)$ & 0.437 & 0.077 & $1093(22.30)$ & 0.461 & 0.089 \\
\hline 5.0 & $1074(5.62)$ & 0.419 & 0.018 & $3087(8.08)$ & 0.381 & 0.024 & $1856(11.88)$ & 0.384 & 0.031 & $832(16.98)$ & 0.402 & 0.039 \\
\hline 5.1 & $629(3.62)$ & 0.377 & 0 & $2061(5.39)$ & 0.339 & 0 & $1300(8.32)$ & 0.335 & 0 & $631(12.87)$ & 0.357 & 0 \\
\hline
\end{tabular}

Table 4. Fasting glucose plasma cutoff values of gestational diabetes mellitus diagnosis according to age categories.

\begin{tabular}{|l|l|l|l|l|l|l|l|}
\hline BMI $\left(\mathbf{k g} / \mathbf{m}^{2}\right)$ & GDM (n) & No-GDM (n) & P value & $\begin{array}{l}\text { Area Under } \\
\text { ROC curve }\end{array}$ & 95CI & SE & P value \\
\hline$<18.5$ & $1511(10.5)$ & 12841 & & 0.66 & $0.647-0.680$ & 0.008 & $<0.001$ \\
\hline $18.5-23.9$ & $8657(16.6)$ & 43595 & $<0.001$ & 0.74 & $0.731-0.744$ & 0.003 & $<0.001$ \\
\hline $24.0-27.9$ & $2743(29.1)$ & 6674 & & 0.81 & $0.794-0.815$ & 0.005 & $<0.001$ \\
\hline$\geq 28.0$ & $657(35.7)$ & 1181 & & 0.83 & $0.811-0.854$ & 0.011 & $<0.001$ \\
\hline
\end{tabular}

Table 5. The receiver operation characteristic curve of the participants among different BMI. BMI, body mass index; GDM, gestational diabetes mellitus; ROC, receiver operation characteristic; CI, confidence intervals; SE, standard error.

\begin{tabular}{|c|c|c|c|c|c|c|c|c|c|c|c|c|}
\hline \multirow[b]{2}{*}{$\begin{array}{l}\text { Cutoff } \\
\text { point } \\
(\mathrm{mmol} / \mathrm{L})\end{array}$} & \multicolumn{3}{|l|}{$<18.5 \mathrm{~kg} / \mathrm{m}^{2}$} & \multicolumn{3}{|c|}{$18.5-23.9 \mathrm{~kg} / \mathrm{m}^{2}$} & \multicolumn{3}{|c|}{$24-27.9 \mathrm{~kg} / \mathrm{m}^{2}$} & \multicolumn{3}{|l|}{$\geq 28.0 \mathrm{~kg} / \mathrm{m}^{2}$} \\
\hline & $\begin{array}{l}\text { At or above } \\
\text { the value, } \\
\mathrm{n}(\%)\end{array}$ & Sensitivity & 1-Specificity & $\begin{array}{l}\text { At or above } \\
\text { the value, } \\
\text { n (\%) }\end{array}$ & Sensitivity & 1-Specificity & $\begin{array}{l}\text { At or above } \\
\text { the value, } \\
\mathrm{n}(\%)\end{array}$ & Sensitivity & 1-Specificity & $\begin{array}{l}\text { At or above } \\
\text { the value, } \\
\text { n (\%) }\end{array}$ & Sensitivity & 1-Specificity \\
\hline 4.0 & $12677(88.33)$ & 0.932 & 0.878 & $48318(92.47)$ & 0.970 & 0.916 & $9036(95.95)$ & 0.989 & 0.948 & $1801(97.99)$ & 0.991 & 0.974 \\
\hline 4.1 & $11557(80.53)$ & 0.879 & 0.797 & 45349 (86.79) & 0.942 & 0.853 & $8729(92.69)$ & 0.981 & 0.905 & $1760(95.76)$ & 0.986 & 0.942 \\
\hline 4.2 & 10042 (69.97) & 0.815 & 0.686 & $41123(78.70)$ & 0.904 & 0.764 & $8212(87.20)$ & 0.962 & 0.835 & $1693(92.11)$ & 0.977 & 0.890 \\
\hline 4.3 & $8323(58.03)$ & 0.728 & 0.563 & $35920(68.74)$ & 0.850 & 0.655 & $7557(80.25)$ & 0.935 & 0.748 & $1593(86.67)$ & 0.963 & 0.813 \\
\hline 4.4 & $6499(45.28)$ & 0.639 & 0.431 & $29912(57.25)$ & 0.786 & 0.530 & $6684(70.98)$ & 0.894 & 0.634 & $1460(79.43)$ & 0.927 & 0.721 \\
\hline 4.5 & $4788(33.36)$ & 0.549 & 0.308 & $23695(45.35)$ & 0.708 & 0.403 & $5760(61.17)$ & 0.847 & 0.515 & $1306(71.06)$ & 0.893 & 0.609 \\
\hline 4.6 & $3402(23.70)$ & 0.457 & 0.211 & $17950(34.35)$ & 0.625 & 0.288 & $4781(50.77)$ & 0.785 & 0.394 & $1132(61.59)$ & 0.845 & 0.489 \\
\hline 4.7 & $2246(15.65)$ & 0.370 & 0.131 & 13049 (25.06) & 0.549 & 0.191 & $3845(40.83)$ & 0.720 & 0.280 & $955(51.96)$ & 0.798 & 0.365 \\
\hline 4.8 & $1404(9.78)$ & 0.300 & 0.074 & $9101(17.42)$ & 0.476 & 0.114 & $2974(31.58)$ & 0.637 & 0.184 & $785(42.71)$ & 0738 & 0.254 \\
\hline 4.9 & $846(5.89)$ & 0.255 & 0.036 & $6166(11.80)$ & 0.412 & 0.060 & $2214(23.51)$ & 0.570 & 0.097 & $638(34.71)$ & 0.680 & 0.162 \\
\hline 5.0 & $504(3.51)$ & 0.216 & 0.014 & $4141(7.93)$ & 0.363 & 0.023 & $1692(17.97)$ & 0.511 & 0.043 & $512(27.86)$ & 0.635 & 0.080 \\
\hline 5.1 & $288(2.01)$ & 0.191 & 0 & $2759(5.28)$ & 0.319 & 0 & $1257(13.35)$ & 0.335 & 0 & $380(20.67)$ & 0.578 & 0 \\
\hline
\end{tabular}

Table 6. Fasting glucose plasma cutoff values of gestational diabetes mellitus diagnosis according to body mass index categories.

$5.1 \mathrm{mmol} / \mathrm{L}$ was to establish the diagnosis of GDM based on the IADPSG criteria was not possible in China. If we use these criteria, there is a bigger possibility that the diagnosis of GDM in some pregnant women will be missed. Any local adaptations of these criteria will have to be dependent on the exact local data of the population under consideration.

Additionally, the Ministry of Health in China published the GDM diagnostic criteria in 2011, which stated that if FPG value was greater than or equal to $5.1 \mathrm{mmol} / \mathrm{L}$, immediately, the pregnant women can be diagnosed as having GDM and if FPG value was greater than or equal to $4.4 \mathrm{mmol} / \mathrm{L}$ and less than $5.1 \mathrm{mmol} / \mathrm{L}$, the 75 -g OGTT must be performed in pregnant women ${ }^{22}$. Our research found that if FPG level was greater than or equal to $5.1 \mathrm{mmol} / \mathrm{L}$, 
immediately, pregnant women can be diagnosed as having GDM with a specificity of $100 \%$. Additionally, if FPG value was less than or equal to $4.5 \mathrm{mmol} / \mathrm{L}$, pregnant women can be ruled out in the diagnosis of GDM with a sensitivity of $72.7 \%$. In view of the above results, we conclude that with the FPG values between 4.5 and $5.1 \mathrm{mmol} / \mathrm{L}$, an optimal threshold to rule out or identify GDM in China. This threshold range will reduce the performance of a number of OGTTs by about $50.37 \%$. Interestingly, one study reported that an FPG value of $4.4 \mathrm{mmol} / \mathrm{L}$ should be used as the optimal cutoff value, which could reduce the performance of a number of OGTTs by about $50.3 \%$ with the probability that the diagnosis of GDM to about $12.2 \%$ of pregnant women may be missed ${ }^{15}$. Although the threshold of FPG value is different, the proportion of avoiding performance of OGTT is similar.

The study had some advantages. The major advantage was that its data were derived from a registered system with a large sample size, which registered Chinese pregnant women who came from the countryside and city to avoid selection bias. Moreover, it was the first research to evaluate the sensitivity and specificity of FPG value to establish the diagnosis of GDM in China with registered data, which had strong public health significance.

The study also had some limitations. Firstly, this study is a retrospective design that included unavoidable selection bias. Secondly, all data were from the MBRX, and pre-pregnancy BMI of Chinese differs from other population; hence, there was a lack of data from other regions. Thirdly, the effects of other factors on incidence of GDM are unavailable, such as physical activity or dietary habit.

As a conclusion, FPG test, with a high sensitivity and specificity, is used as an ideal GDM screening tool for low-resource countryside that simplifies the demanding algorithm for the establishment of the diagnosis of GDM. Moreover, for maternal age and pre-pregnancy BMI categories, FPG $\geq 4.5 \mathrm{mmol} / \mathrm{L}$ could be as an optimal predictor for GDM in all groups with a high sensitivity, which could improve the diagnostic rate and reduce the health burden of the Chinese societies and families.

\section{Data availability}

Data are available upon request. Please contact Xue-jun Li, professor, xmlixuejun@163.com.

Received: 8 January 2019; Accepted: 15 October 2019;

Published online: 05 November 2019

\section{References}

1. American Diabetes A. Gestational diabetes mellitus. Diabetes Care. 27(Suppl 1), S88-90 (2004).

2. International Diabetes Federation. IDF Diabetes Atlas, 8th Edition, http://www.diabetesatlas.org/resources/2017-atlas.html. (Accessed on 20 October 2018).

3. Nguyen, C. L. et al. Prevalence of Gestational Diabetes Mellitus in Eastern and Southeastern Asia: A Systematic Review and MetaAnalysis. J Diabetes Res. 2018, 6536974 (2018)

4. Eades, C. E., Cameron, D. M. \& Evans, J. M. M. Prevalence of gestational diabetes mellitus in Europe: A meta-analysis. Diabetes Res Clin Pract. 129, 173-181 (2017).

5. Leng, J. et al. Prevalence of gestational diabetes mellitus and its risk factors in Chinese pregnant women: a prospective populationbased study in Tianjin, China. PLoS One. 10, e0121029 (2015).

6. Xu, T. et al. The short-term health and economic burden of gestational diabetes mellitus in China: a modelling study. BMJ Open. 7, e018893 (2017).

7. National Bureau of Statistics of China. China statistical yearbook 2015, http://www.stats.gov.cn/tjsj/ndsj/2015/indexeh.htm. Accessed on 21 October 2018

8. American Diabetes A. Diagnosis and classification of diabetes mellitus. Diabetes Care. 37(Suppl 1), S81-90 (2014).

9. Buckley, B. S. et al. Gestational diabetes mellitus in Europe: prevalence, current screening practice and barriers to screening. A review. Diabet Med. 29, 844-854 (2012).

10. Farrar, D. et al. Different strategies for diagnosing gestational diabetes to improve maternal and infant health. Cochrane Database Syst Rev. 1, CD007122 (2015).

11. Round, J. A. et al. Screening for gestational diabetes mellitus: cost-utility of different screening strategies based on a woman's individual risk of disease. Diabetologia. 54, 256-263 (2011).

12. Agarwal, M. M., Dhatt, G. S. \& Othman, Y. Gestational diabetes in a tertiary care hospital: implications of applying the IADPSG criteria. Arch Gynecol Obstet. 286, 373-378 (2012).

13. Rey, E. Screening for gestational diabetes mellitus. A simple test may make it easier to study whether screening is worthwhile. $B M J$. 319, 798-799 (1999).

14. Zhu, W. W. et al. Evaluation of the value of fasting plasma glucose in the first prenatal visit to diagnose gestational diabetes mellitus in china. Diabetes Care. 36, 586-590 (2013).

15. Zhu, W. W. et al. Fasting plasma glucose at 24-28 weeks to screen for gestational diabetes mellitus: new evidence from China. Diabetes Care. 36, 2038-2040 (2013).

16. Xu, X. et al. Prevalence and Sociodemographic and Lifestyle Determinants of Anemia during Pregnancy: A Cross-Sectional Study of Pregnant Women in China. Int J Environ Res Public Health. 13 (2016)

17. Laopaiboon, M. et al. Advanced maternal age and pregnancy outcomes: a multicountry assessment. BJOG. 121(Suppl 1), 49-56 (2014).

18. Black, M. H. et al. The relative contribution of prepregnancy overweight and obesity, gestational weight gain, and IADPSG-defined gestational diabetes mellitus to fetal overgrowth. Diabetes Care. 36, 56-62 (2013).

19. Gibson, K. S., Waters, T. P. \& Catalano, P. M. Maternal weight gain in women who develop gestational diabetes mellitus. Obstet Gynecol. 119, 560-565 (2012).

20. Shah, A. et al. The association between body mass index and gestational diabetes mellitus varies by race/ethnicity. Am J Perinatol. 28, 515-520 (2011).

21. Hedderson, M. et al. Racial/ethnic disparities in the prevalence of gestational diabetes mellitus by BMI. Diabetes Care. 35, 1492-1498 (2012).

22. Yang, H. X. Diagnostic criteria for gestational diabetes mellitus (WS 331-2011). Chin Med J (Engl). 125, 1212-1213 (2012).

23. Consultation WHOE. Appropriate body-mass index for Asian populations and its implications for policy and intervention strategies. Lancet. 363, 157-163 (2004).

24. McIntyre, H. D. et al. Issues With the Diagnosis and Classification of Hyperglycemia in Early Pregnancy. Diabetes Care. 39, 53-54 (2016).

25. Virally, M. \& Laloi-Michelin, M. Methods for the screening and diagnosis of gestational diabetes mellitus between 24 and 28 weeks of pregnancy. Diabetes Metab. 36, 549-565 (2010).

26. Moses, R. G. Gestational diabetes mellitus: implications of an increased frequency with IADPSG criteria. Diabetes Care. 35, 461-462 (2012). 


\section{Acknowledgements}

This work was funded by the National Natural Science Foundation of China [Grant Number: 0070/K16A8035, 0070/K1615020].

\section{Author contributions}

B.Y. and Y.-X., X. collected and analyzed data, wrote the first daft, and created the table. Y.-L.C., W.-J.S. and Y.-X. H. designed the study and directed statistical analyses of the data. M.-L.Z., B.-K.H. and L.-L.H. analyzed and interpreted the data. H.-Q.S. and X.-J.L. designed the study, and revised the submission. All authors contributed to the discussion, and approved the final manuscript.

\section{Competing interests}

The authors declare no competing interests.

\section{Additional information}

Correspondence and requests for materials should be addressed to H.-q.S. or X.-j.L.

Reprints and permissions information is available at www.nature.com/reprints.

Publisher's note Springer Nature remains neutral with regard to jurisdictional claims in published maps and institutional affiliations.

Open Access This article is licensed under a Creative Commons Attribution 4.0 International License, which permits use, sharing, adaptation, distribution and reproduction in any medium or format, as long as you give appropriate credit to the original author(s) and the source, provide a link to the Creative Commons license, and indicate if changes were made. The images or other third party material in this article are included in the article's Creative Commons license, unless indicated otherwise in a credit line to the material. If material is not included in the article's Creative Commons license and your intended use is not permitted by statutory regulation or exceeds the permitted use, you will need to obtain permission directly from the copyright holder. To view a copy of this license, visit http://creativecommons.org/licenses/by/4.0/.

(C) The Author(s) 2019 